Article

\title{
A Nonlinear Elastic Model for Triaxial Compressive Properties of Artificial Methane-Hydrate-Bearing Sediment Samples
}

\author{
Kuniyuki Miyazaki $^{1, *}$, Norio Tenma ${ }^{2}$, Kazuo Aoki $^{2}$ and Tsutomu Yamaguchi ${ }^{3}$ \\ 1 Institute for Geo-Resources and Environment, National Institute of Advanced Industrial Science \\ and Technology, 1-1-1 Higashi, Tsukuba, Ibaraki 305-8567 Japan \\ 2 Methane Hydrate Research Center, National Institute of Advanced Industrial Science and \\ Technology, 16-1 Onogawa, Tsukuba, Ibaraki 305-8569 Japan; \\ E-Mails: tenma-n@aist.go.jp (N.T.); aoki-kazuo@aist.go.jp (K.A.) \\ 3 Department of Environmental Science, Toho University, 2-2-1 Miyama, Funabashi, \\ Chiba 274-8510 Japan; E-Mail: yamaguchi@env.sci.toho-u.ac.jp \\ * Author to whom correspondence should be addressed; E-Mail: miyazaki-kuniyuki@aist.go.jp; \\ Tel.: +81-29-861-8753; Fax: +81-29-861-8738.
}

Received: 28 June 2012; in revised form: 1 October 2012 / Accepted: 16 October 2012 /

Published: 19 October 2012

\begin{abstract}
A constitutive model for marine sediments containing natural gas hydrate is essential for the simulation of the geomechanical response to gas extraction from a gas-hydrate reservoir. In this study, the triaxial compressive properties of artificial methane-hydrate-bearing sediment samples reported in an earlier work were analyzed to examine the applicability of a nonlinear elastic constitutive model based on the Duncan-Chang model. The presented model considered the dependences of the mechanical properties on methane hydrate saturation and effective confining pressure. Some parameters were decided depending on the type of sand forming a specimen. The behaviors of lateral strain versus axial strain were also formulated as a function of effective confining pressure. The constitutive model presented in this study will provide a basis for an elastic analysis of the geomechanical behaviors of the gas-hydrate reservoir in the future study, although it is currently available to a limited extent.
\end{abstract}

Keywords: methane hydrate; triaxial compressive property; stress-strain relationship; constitutive model; Duncan-Chang model 


\section{Introduction}

Natural gas hydrates are anticipated to be a promising energy resource [1-4]. The mechanical property of a gas hydrate reservoir is considered to be essential for sustainable production, because it will affect the stability of a wellbore or other subsea structures, the occurrence of geohazards and gas productivity [5-8].

A constitutive model for gas-hydrate-bearing sediments is required for the simulation of the geomechanical response to gas extraction from a gas-hydrate reservoir. Laboratory studies are useful for constructing a constitutive model for gas-hydrate-bearing sediments. However, few constitutive model for gas-hydrate-bearing sediments has been published [9], although there have been reports on laboratory studies concerning the triaxial compressive properties of natural and artificial gas-hydrate-bearing sediment samples [10-19].

An elastic constitutive model may be practically useful for the preliminary simulation of the mechanical behavior of a reservoir on the condition that we use it with particular attention to the applicable range. In this study, the application of the Duncan-Chang model, a nonlinear elastic model, to the analysis of the triaxial compressive properties of artificial methane-hydrate-bearing sediment samples reported mainly in an earlier work [19] was examined. The dependences of the mechanical properties on methane hydrate saturation and effective confining pressure were considered.

\section{Review of Triaxial Compression Test}

The methods and results of triaxial compression test for artificial methane-hydrate-bearing sediments were described in our previous studies [12,14,16-19]. In this section, the test methods and results are briefly described.

\subsection{Test Methods}

Host specimens were prepared by freezing a cylindrical unsaturated sand specimen. The skeleton of each specimen was formed by Toyoura sand (average particle size $D_{50}=230 \times 10^{-6} \mathrm{~m}$, fine fraction content $\left.F_{c}=0.0 \%\right)$, No. 7 silica sand $\left(D_{50}=205 \times 10^{-6} \mathrm{~m}, F_{c}=1.1 \%\right)$ or No. 8 silica sand $\left(D_{50}=130 \times 10^{-6} \mathrm{~m}, F_{c}=11.5 \%\right)$. These three types of sand contain $\mathrm{SiO}_{2}$ as a major component. The relative density of each host specimen was over $96 \%$. The average porosities of the host specimens formed by Toyoura sand, No. 7 silica sand and No. 8 silica sand were 37.8\%, 38.6\% and 41.2\%, respectively. The relative density of each host specimen was over $96 \%$. Each host specimen was $50 \mathrm{~mm}$ in diameter and $100 \mathrm{~mm}$ in length.

The artificial methane-hydrate-bearing sediment samples, which are hereafter referred to as a "hydrate-sand specimen," were prepared from the frozen host sand by the following procedure. First, a cell pressure of $0.5 \mathrm{MPa}, 1 \mathrm{MPa}, 2 \mathrm{MPa}$ or $3 \mathrm{MPa}$ was applied. Second, the pore air in the specimen was replaced by the methane at $268 \mathrm{~K}$ or less. Third, the pore gas pressure was increased to $8 \mathrm{MPa}$ at a rate of approximately $0.7 \mathrm{MPa} / \mathrm{min}$, whereas the cell pressure was increased to $8.5 \mathrm{MPa}, 9 \mathrm{MPa}$, $10 \mathrm{MPa}$ or $11 \mathrm{MPa}$ at the same rate. Forth, the temperature inside the triaxial cell was increased to $278 \mathrm{~K}$. The cell pressure, pore gas pressure and temperature were then kept constant for $24 \mathrm{~h}$ during the hydrate formation period. The pore gas pressure was controlled by a pressure-reducing valve 
attached to the methane gas cylinder. Finally, water was injected into the specimen to replace the residual gaseous methane in the pores of the specimen. We also prepared "sand specimens," i.e., water-saturated specimens of densely packed sand sediment without hydrate by omitting the methane hydrate formation process from the above-described procedure.

Axial loading was conducted at an axial strain rate of $0.1 \% / \mathrm{min}$ under a drained condition while maintaining the pore pressure at $8 \mathrm{MPa}$, the cell pressure at $8.5 \mathrm{MPa}, 9 \mathrm{MPa}, 10 \mathrm{MPa}$ or $11 \mathrm{MPa}$ and the temperature at $278 \mathrm{~K}$. The methane hydrate existing in the specimen was dissociated by reducing pore pressure after the axial loading. Then, the volume of released methane was measured using a gas flow meter. Assuming that all the released gas have been converted to the hydrate during the axial loading, the initial volume of the methane hydrate formed in the specimen, and thus the methane hydrate saturation $S_{h}$, was calculated from the volume of released methane, where $S_{h}$ is the initial volume percentage of methane hydrate in the pores of the specimen. The methane hydrate saturation $S_{h}$ of each hydrate-sand specimen used in this study was below $60 \%$.

\subsection{Test Results}

Figure 1 shows the deviator stress $q$ plotted against the axial strain $\varepsilon_{a}$ and lateral strain $\varepsilon_{l}$ for the sand specimens (a: $S_{h}=0 \%$ ) and hydrate-sand specimens (b: $S_{h}=27 \%-34 \%$, c: $S_{h}=41 \%-45 \%$ ) formed by Toyoura sand under the effective confining pressures $\sigma_{3}{ }^{\prime}$ of $0.5 \mathrm{MPa}, 1 \mathrm{MPa}, 2 \mathrm{MPa}$ and $3 \mathrm{MPa}$. In Figure 1, as well as in Figures 2-5, solid lines represent the experimental results reported in the earlier work [19] and broken lines represent the calculated results with the constitutive model which will be described later. Axial/lateral strain was calculated by dividing the axial/lateral displacement measured with the LVDTs using the initial height/diameter of the specimen in this paper. Note that the lateral displacement was measured at the middle height of the specimen. A positive strain denotes compression in this paper. The $q$ increases and the slopes of the $q-\varepsilon_{a}$ and $q-\varepsilon_{l}$ curves decrease until $q$ reaches a peak, and then $q$ gradually decreases. Under a given $\sigma_{3}$, the larger the $S_{h}$, the larger the strength (maximum deviator stress) $q_{f}$ and the initial tangent elastic modulus $E_{i}$. For a given $S_{h}$, the specimen has a larger $q_{f}$ and larger $E_{i}$ and becomes more ductile under a higher $\sigma_{3}$ ', as in the case of other geological materials.

Figure 2 shows the $\varepsilon_{l}$ plotted against the $\varepsilon_{a}$ for the sand specimens (a: $S_{h}=0 \%$ ) and hydrate-sand specimens (b: $S_{h}=27 \%-34 \%$, c: $S_{h}=41 \%-45 \%$ ) formed by Toyoura sand under the $\sigma_{3}$ ' of $0.5 \mathrm{MPa}$, $1 \mathrm{MPa}, 2 \mathrm{MPa}$ and $3 \mathrm{MPa}$. All the $\varepsilon_{l}-\varepsilon_{a}$ curves are concave upward in this graph. A specimen of higher $S_{h}$ has a tendency to expand further in the lateral direction. It is also found that $\varepsilon_{l}$ tends to decrease with increasing $\sigma_{3}$ ' at a given $\varepsilon_{a}$. 
Figure 1. Experimental (solid lines) and calculated (broken lines) deviator stress $q$ versus axial strain $\varepsilon_{a}$ and lateral strain $\varepsilon_{l}$ for specimens formed by Toyoura sand with methane hydrate saturation $S_{h}$ of (a) $0 \%$; (b) $27 \%-34 \%$ and (c) $41 \%-45 \%$. Experimental results are taken from the reference [19].
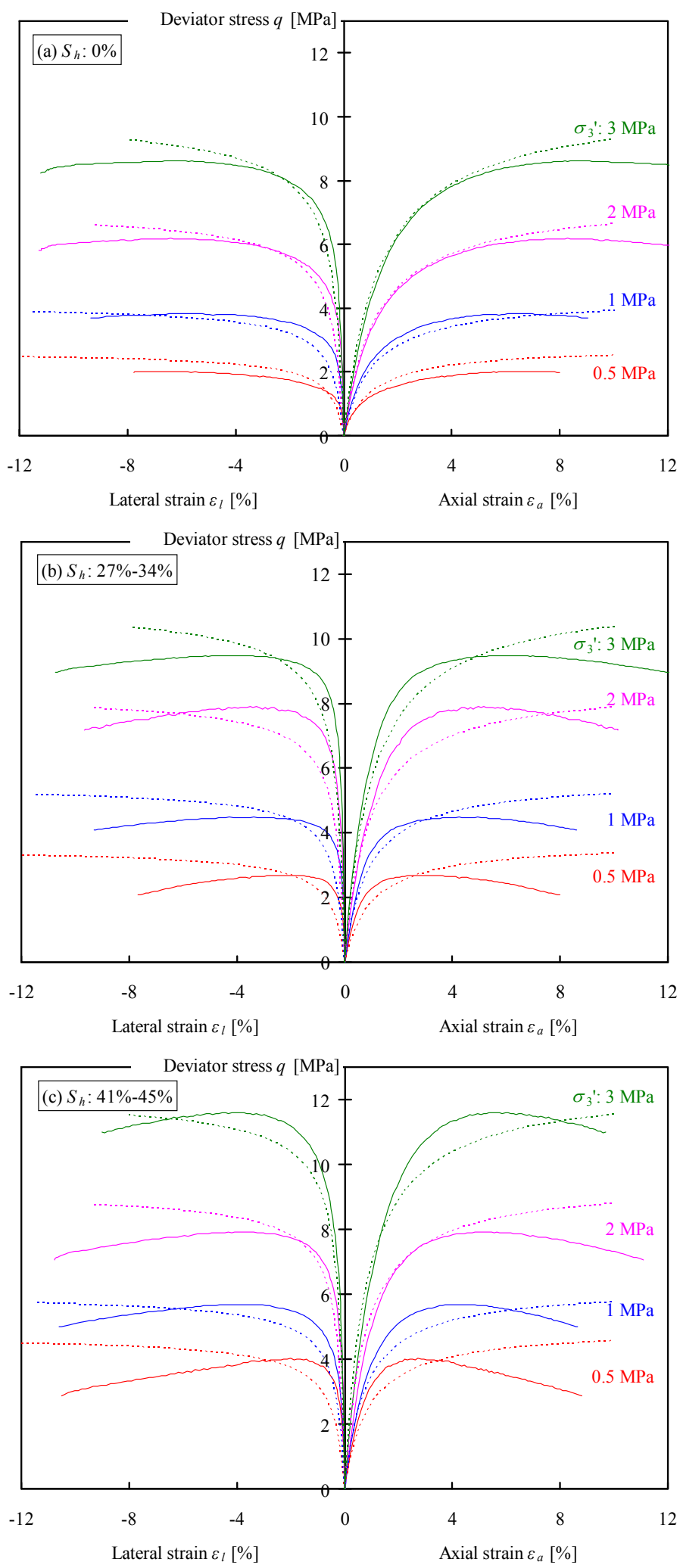
Figure 2. Experimental (solid lines) and calculated (broken lines) lateral strain $\varepsilon_{l}$ versus axial strain $\varepsilon_{a}$ for specimens formed by Toyoura sand with methane hydrate saturation $S_{h}$ of (a) $0 \%$; (b) $27 \%-34 \%$ and (c) $41 \%-45 \%$. Experimental results are taken from the reference [19].
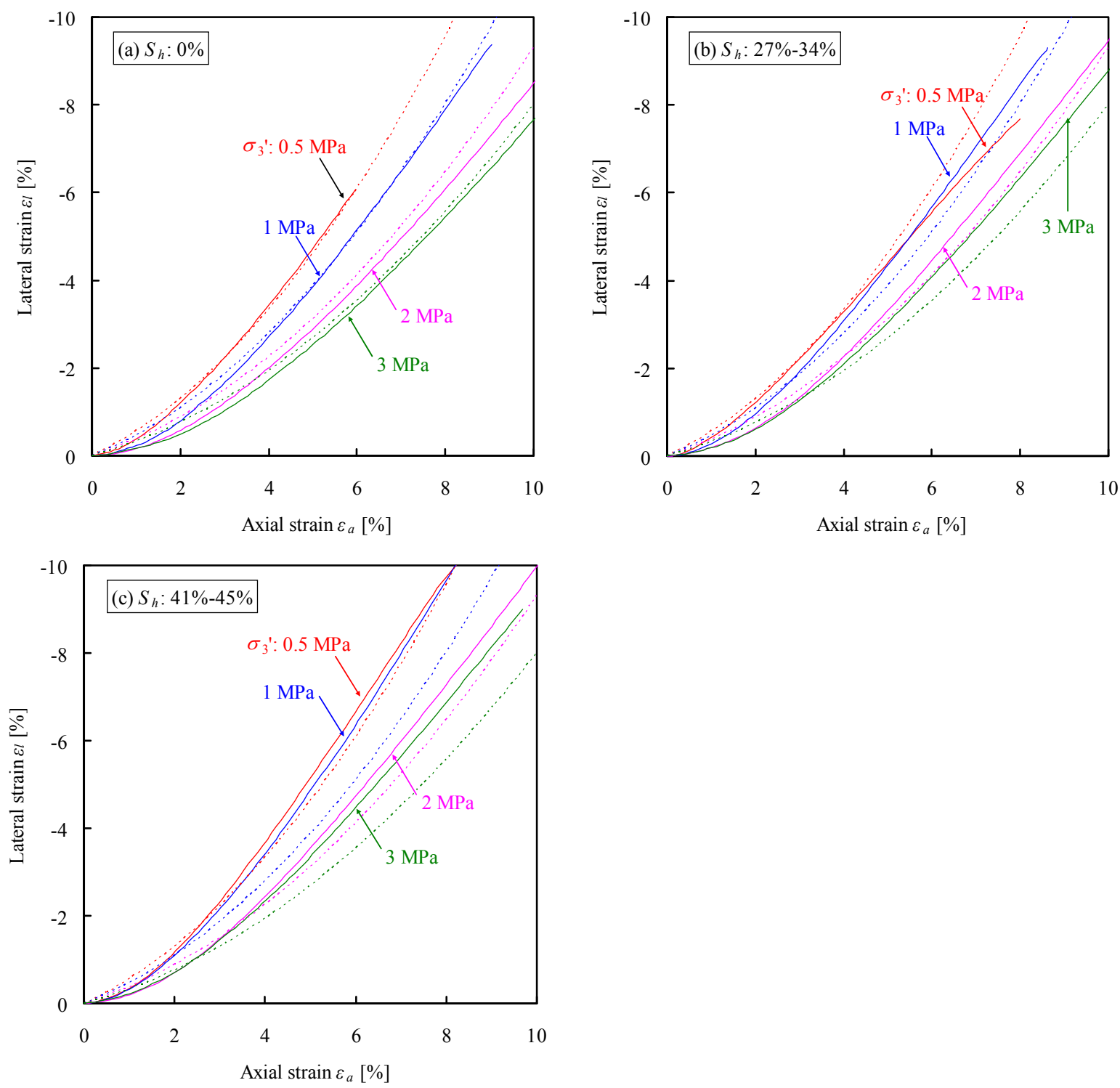

Figures 3 and 4 show the $q-\varepsilon_{a}$ and $q-\varepsilon_{l}$ curves and the $\varepsilon_{l}-\varepsilon_{a}$ curves, respectively, for the specimens formed by No. 7 silica sand. Figures 5 and 6 show the $q-\varepsilon_{a}$ and $q-\varepsilon_{l}$ curves and the $\varepsilon_{l}-\varepsilon_{a}$ curves, respectively, for the specimens formed by No. 8 silica sand. It is found that the relationships among the $q, \varepsilon_{a}$ and $\varepsilon_{l}$ for the specimens formed by No. 7 and No. 8 silica sand are qualitatively similar to those for the specimens formed by Toyoura sand. 
Figure 3. Experimental (solid lines) and calculated (broken lines) deviator stress $q$ versus axial strain $\varepsilon_{a}$ and lateral strain $\varepsilon_{l}$ for specimens formed by No. 7 silica sand with methane hydrate saturation $S_{h}$ of (a) $0 \%$; (b) 23\%-28\% and (c) $49 \%$. Experimental results are taken from the reference [19].
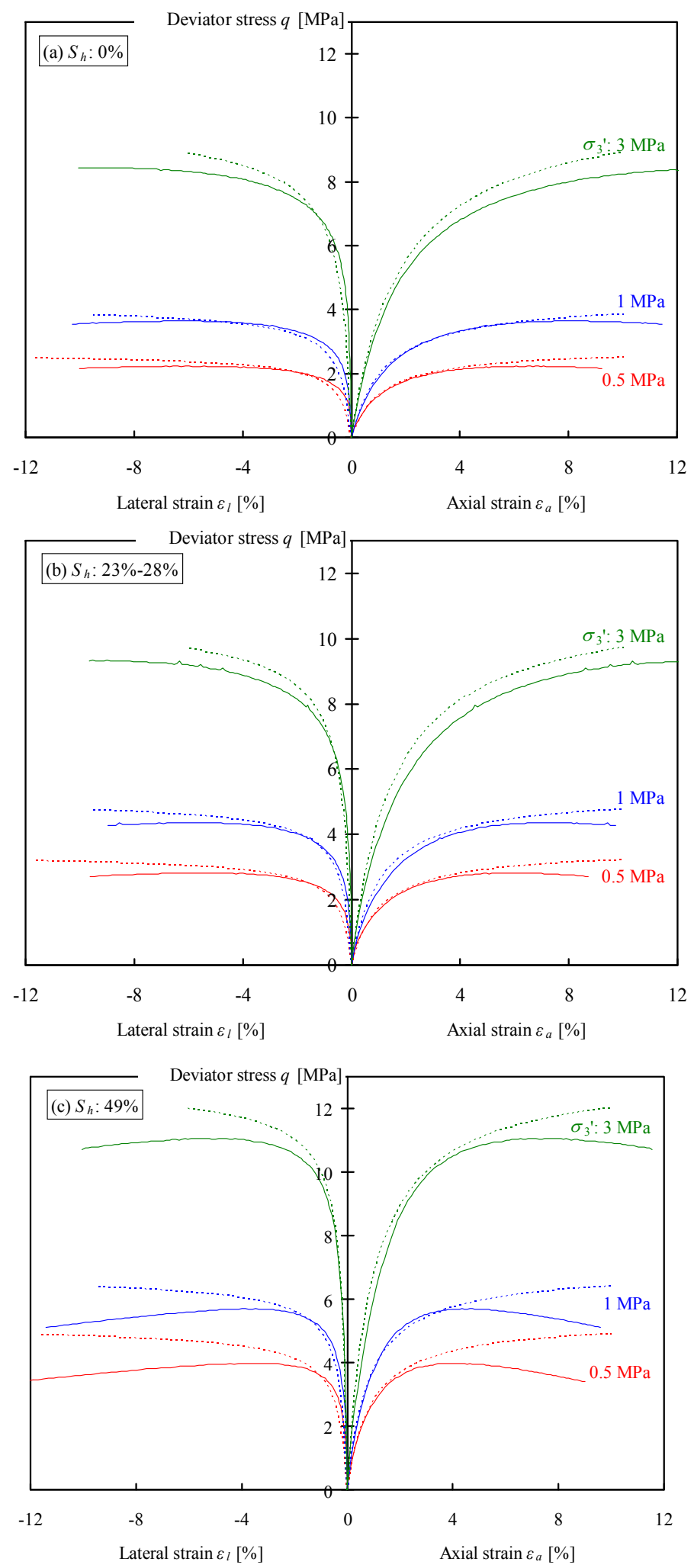
Figure 4. Experimental (solid lines) and calculated (broken lines) lateral strain $\varepsilon_{l}$ versus axial strain $\varepsilon_{a}$ for specimens formed by No. 7 silica sand with methane hydrate saturation $S_{h}$ of (a) $0 \%$; (b) $23 \%-28 \%$ and (c) $49 \%$. Experimental results are taken from the reference [19].
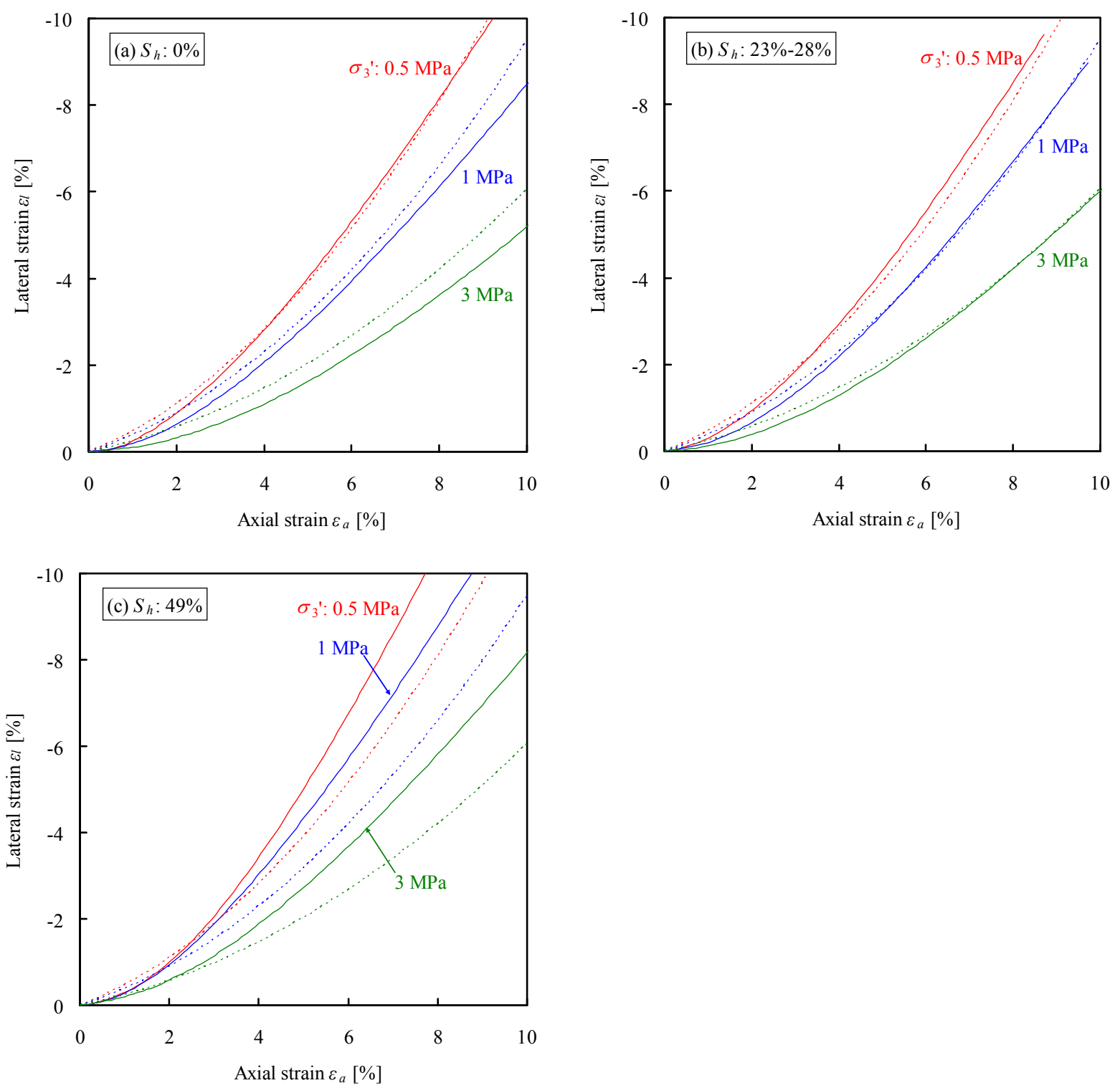
Figure 5. Experimental (solid lines) and calculated (broken lines) deviator stress $q$ versus axial strain $\varepsilon_{a}$ and lateral strain $\varepsilon_{l}$ for specimens formed by No. 8 silica sand with methane hydrate saturation $S_{h}$ of (a) $0 \%$; (b) 19\%-23\% and (c) 44\%-50\%. Experimental results are taken from the reference [19].
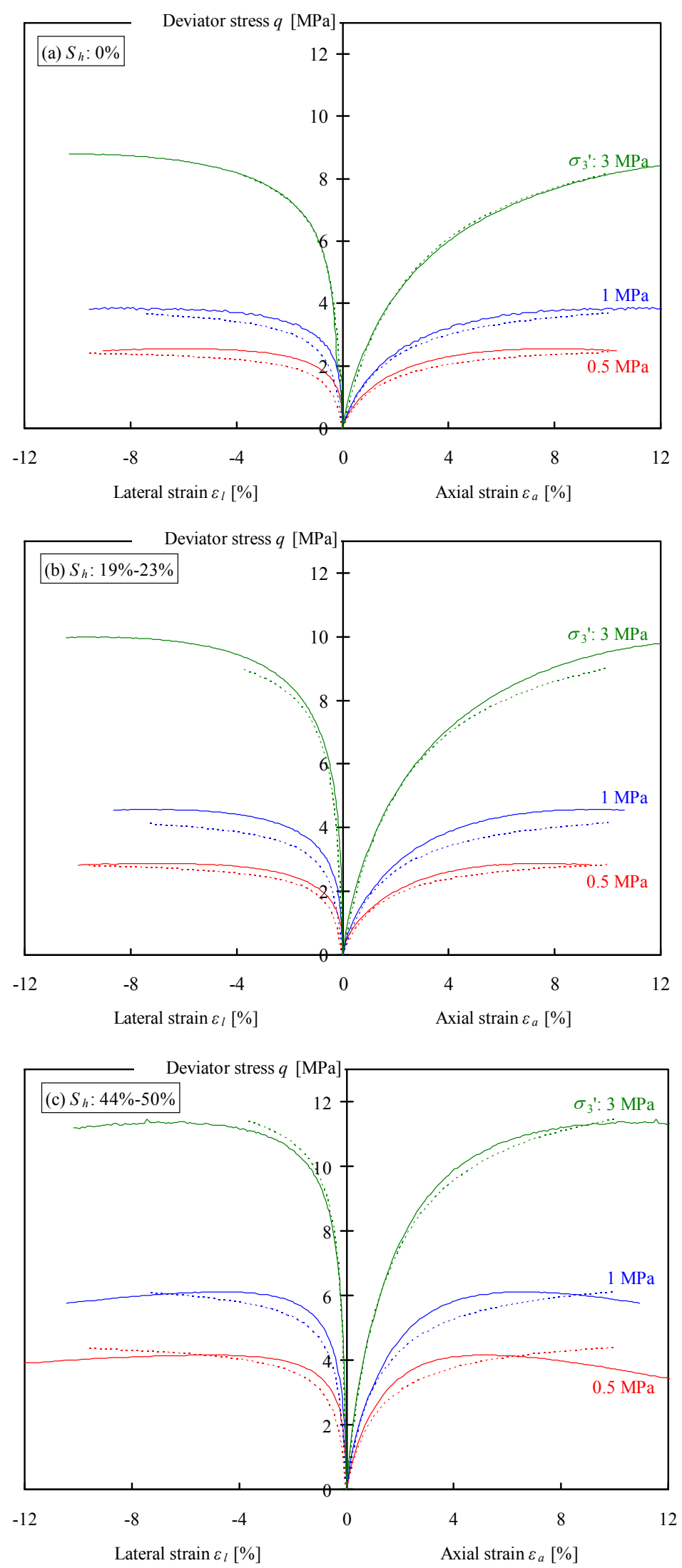
Figure 6. Experimental (solid lines) and calculated (broken lines) lateral strain $\varepsilon_{l}$ versus axial strain $\varepsilon_{a}$ for specimens formed by No. 8 silica sand with methane hydrate saturation $S_{h}$ of (a) $0 \%$; (b) $19 \%-23 \%$ and (c) $44 \%-50 \%$. Experimental results are taken from the reference [19].
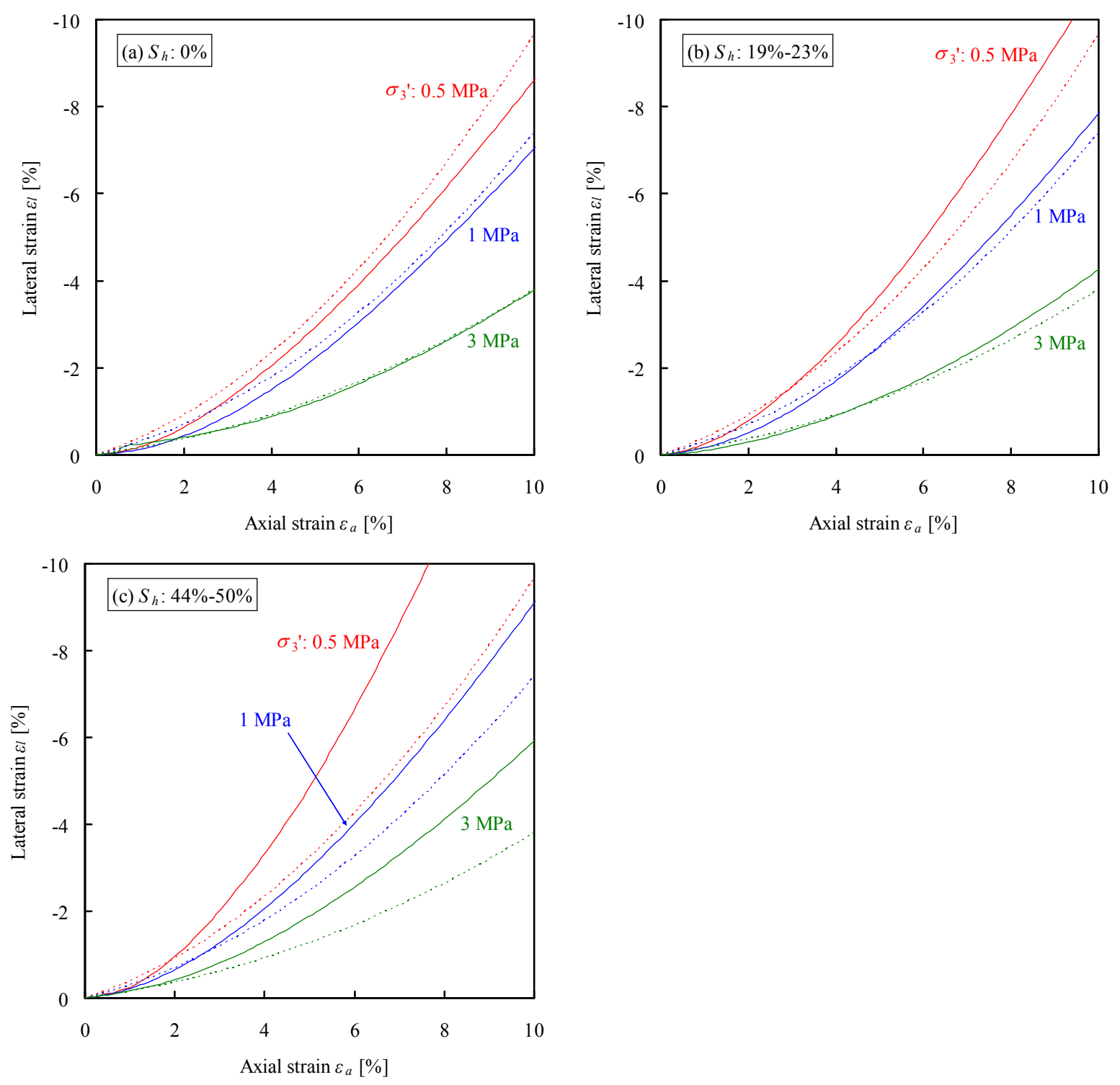

Figure 7 shows the strength $q_{f}$ plotted against the methane hydrate saturation $S_{h}$ for the specimens formed by Toyoura sand, No. 7 silica sand and No. 8 silica sand as the skeleton. The strength $q_{f}$ increases with $S_{h}$ under each effective confining pressure $\sigma_{3}$ '. It can be seen that there is little difference in strength among the three types of sand and hydrate-sand specimens formed by Toyoura sand, No. 7 silica sand and No. 8 silica sand at the same $S_{h}$ and $\sigma_{3}$ '. 
Figure 7. Strength $q_{f}$ versus methane hydrate saturation $S_{h}$. Experimental results are taken from the reference [19].

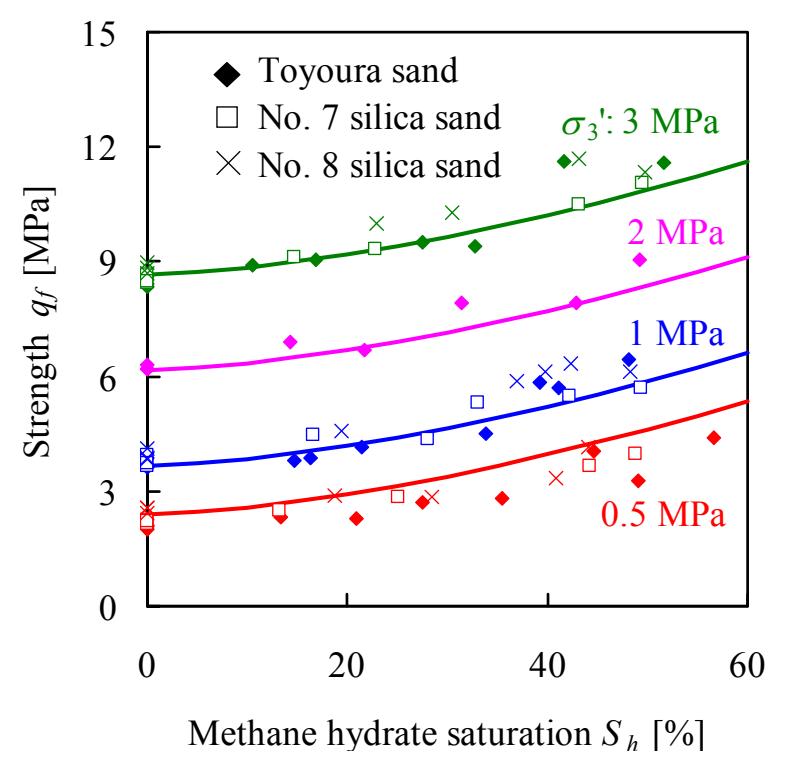

\section{Nonlinear Elastic Constitutive Model}

\subsection{Duncan-Chang Model}

Miyazaki et al. [20] suggested a possibility of application of Duncan-Chang model to the stress-strain relationships of hydrate-sand specimen formed by Toyoura sand. Duncan and Chang [21] described the following nonlinear elastic constitutive model:

$$
q=\frac{\varepsilon_{a}}{a+b \cdot \varepsilon_{a}}
$$

where $a$ and $b$ are coefficients related to the initial tangent elastic modulus $E_{i}$ and the asymptotic value of the deviator stress $q_{u l t}$, as shown by:

$$
\begin{aligned}
& a=\frac{1}{E_{i}} \\
& b=\frac{1}{q_{u l t}}
\end{aligned}
$$

Equation (1) can be rewritten as:

$$
\frac{\varepsilon_{a}}{q}=a+b \cdot \varepsilon_{a}
$$

Thus, $a$ and $b$, and ultimately $E_{i}$ and $q_{u l t}$, can be determined by the linear approximation of the experimental $\left(\varepsilon_{a} / q\right)-\varepsilon_{a}$ data. In this study, the $\left(\varepsilon_{a} / q\right)-\varepsilon_{a}$ data at the stress level $\left(q / q_{f}\right)$ in the range of $70 \%$ to $95 \%$ were used to determine $a$ and $b$, as recommended in Duncan and Chang's study [21]. 


\subsection{Strength}

The four curves shown in Figure 7 represent the calculated strengths for the effective confining pressures $\sigma_{3}$ ' of $0.5 \mathrm{MPa}, 1 \mathrm{MPa}, 2 \mathrm{MPa}$ and $3 \mathrm{MPa}$ with the following equations as functions of $\sigma_{3}$ ' and $S_{h}$ :

$$
\begin{gathered}
q_{f}=\frac{2 \cdot \cos \varphi}{1-\sin \varphi} c_{0}+\alpha \cdot S_{h}{ }^{\beta}+\frac{2 \cdot \sin \varphi}{1-\sin \varphi} \sigma_{3}{ }^{\prime} \\
c_{0}=0.30 \mathrm{MPa} \\
\varphi=33.8^{\circ} \\
\alpha=4.64 \times 10^{-3} \\
\beta=1.58
\end{gathered}
$$

The form of Equation (5) is determined on the basis of the Mohr-Coulomb failure theory and the observation by Masui et al. [14] indicating that the cohesion increases with $S_{h}$ and the internal friction angle $\varphi$ is almost independent of $S_{h}$. The values of the parameters in Equation (5) were determined as Equations (6-9) using all of the experimental data shown in Figure 7.

\subsection{Initial Tangent Elastic Modulus}

Figure 8 shows $E_{i}$, or the inverse of $a$, plotted against the methane hydrate saturation $S_{h}$. It is found that $E_{i}$ shows an increasing trend with $S_{h}$ and $\sigma_{3}$, although quite a variation can be seen. Janbu [22] has shown that the relationship between $E_{i}$ and $\sigma_{3}$ ' may be expressed as:

$$
E_{i}=K \cdot p_{a} \cdot\left(\frac{\sigma_{3}{ }^{\prime}}{p_{a}}\right)^{n}
$$

where $p_{a}=$ atmospheric pressure, $K=$ a modulus number and $n=$ the exponent determining the rate of variation of $E_{i}$ with $\sigma_{3}$,', indicating that $E_{i}$ is proportional to the $n$-th power of $\sigma_{3}$ '. Thus, in this study, it is assumed that $E_{i}$ can be expressed as a function of $S_{h}$ and $\sigma_{3}$ ' as:

$$
E_{i}\left(S_{h}, \sigma_{3}{ }^{\prime}\right)=e_{i}\left(S_{h}\right) \cdot \sigma_{3}{ }^{n}
$$

where $e_{i}\left(S_{h}\right)=$ the initial tangent elastic modulus as a function of $S_{h}$ under $\sigma_{3}$ ' of $1 \mathrm{MPa}$, or $E_{i}\left(S_{h}, 1\right)$. When $S_{h}=0 \%$, the $n$ and $e_{i}$ in Equation (11) for sand specimens formed by Toyoura sand, No. 7 silica sand and No. 8 silica sand are respectively estimated by the least-squares regression:

$$
\begin{gathered}
n=\left\{\begin{array}{l}
0.608 \text { (for Toyoura sand) } \\
0.466 \text { (for No. } 7 \text { silica sand) } \\
0.356 \text { (for No. } 8 \text { silica sand) }
\end{array}\right. \\
e_{i 0}=\left\{\begin{array}{l}
398 \mathrm{MPa} \text { (for Toyoura sand) } \\
344 \mathrm{MPa} \text { (for No. } 7 \text { silica sand) } \\
241 \mathrm{MPa} \text { (for No. } 8 \text { silica sand) }
\end{array}\right.
\end{gathered}
$$

where $e_{i 0}=e_{i}$ for a sand specimen $\left(S_{h}=0 \%\right)$. 
Figure 8. Initial tangent modulus $E_{i}$ versus methane hydrate saturation $S_{h}$ for specimens formed by (a) Toyoura sand; (b) No.7 silica sand and (c) No.8 silica sand. The curves are calculated using Equation (11).
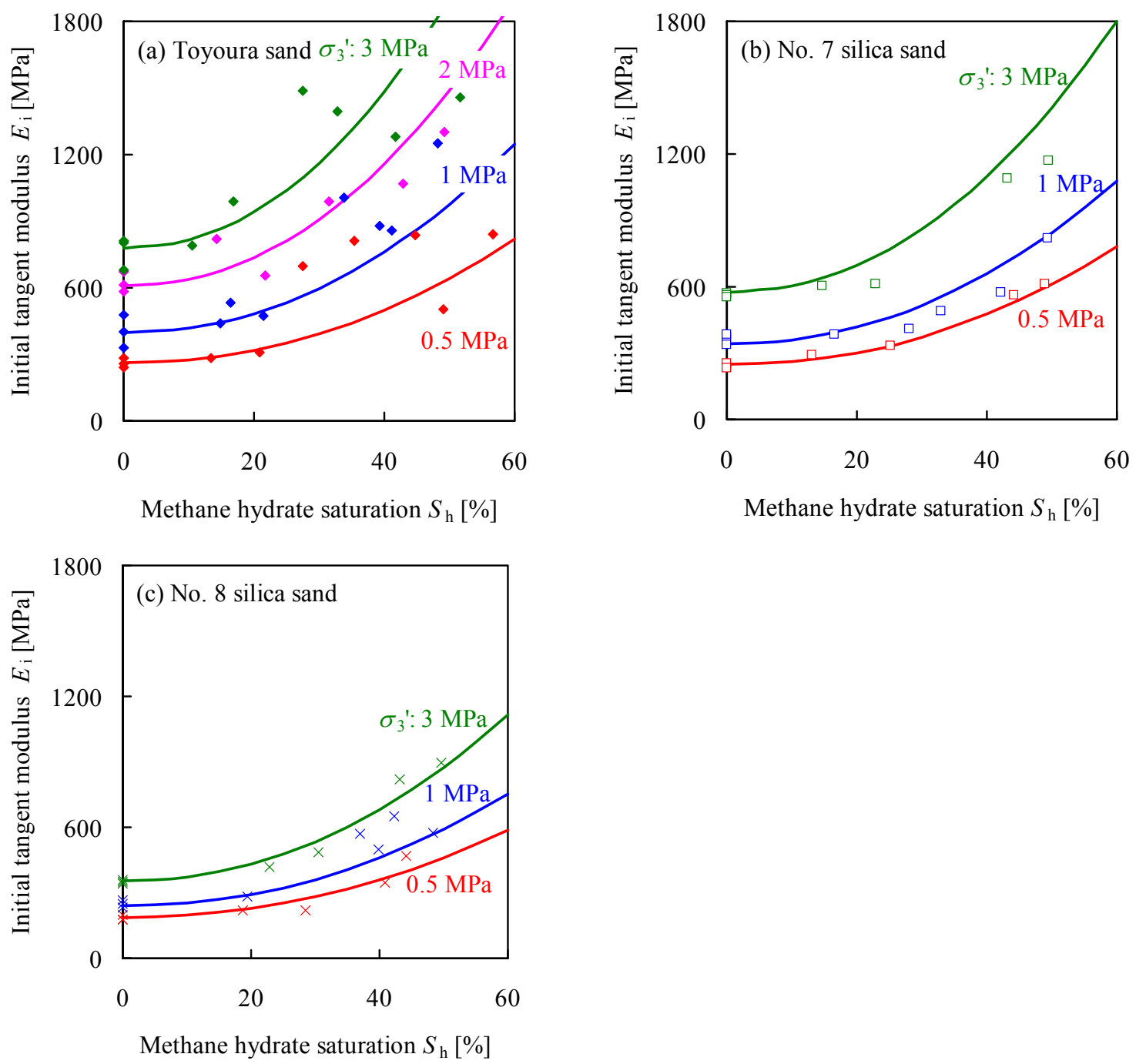

Figure 9 shows the normalized initial tangent elastic modulus $E_{i} *\left(S_{h}\right)$, or the initial tangent modulus divided by $\left(e_{i 0} \cdot \sigma_{3}{ }^{n}\right)$, plotted against $S_{h}$ for the hydrate-sand specimens:

$$
E_{i} *\left(S_{h}\right)=\frac{E_{i}\left(S_{h}, \sigma_{3}{ }^{\prime}\right)}{e_{i 0} \cdot \sigma_{3}{ }^{\prime n}}=\frac{e_{i}\left(S_{h}\right) \cdot \sigma_{3}{ }^{\prime n}}{e_{i 0} \cdot \sigma_{3}{ }^{\prime n}}=\frac{e_{i}\left(S_{h}\right)}{e_{i 0}}
$$

Equation (14) is derived from Equation (11) and indicates that the relationship between $E_{i}^{*}$ and $S_{h}$ is independent of $\sigma_{3}$ '. Because $e_{i 0}$ is equal to $e_{i}$ for a sand specimen, $E_{i}{ }^{*}$ should be 1 at $S_{h}=0 \%$. In this study, it is assumed that the increase of $E_{i}^{*}$ is proportional to $S_{h}$ to the $\delta$-th power:

$$
E_{i} *\left(S_{h}\right)=\frac{e_{i}\left(S_{h}\right)}{e_{i 0}}=1+\gamma \cdot S_{h}^{\delta}
$$

where $\gamma$ and $\delta$ are estimated by the least-squares regression for the $E_{i}{ }^{*}-S_{h}$ shown in Figure 9 as:

$$
\gamma=3.90 \times 10^{-4}
$$




$$
\delta=2.10
$$

Because a wide variation is seen in Figure 9, there are various possible expressions for the $E_{i}{ }^{*}-S_{h}$ relationship other than Equation (15).

Figure 9. Normalized initial tangent elastic modulus $E_{i}^{*}$ versus methane hydrate saturation $S_{h}$ for hydrate-sand specimens. The curve is calculated using Equation (15).

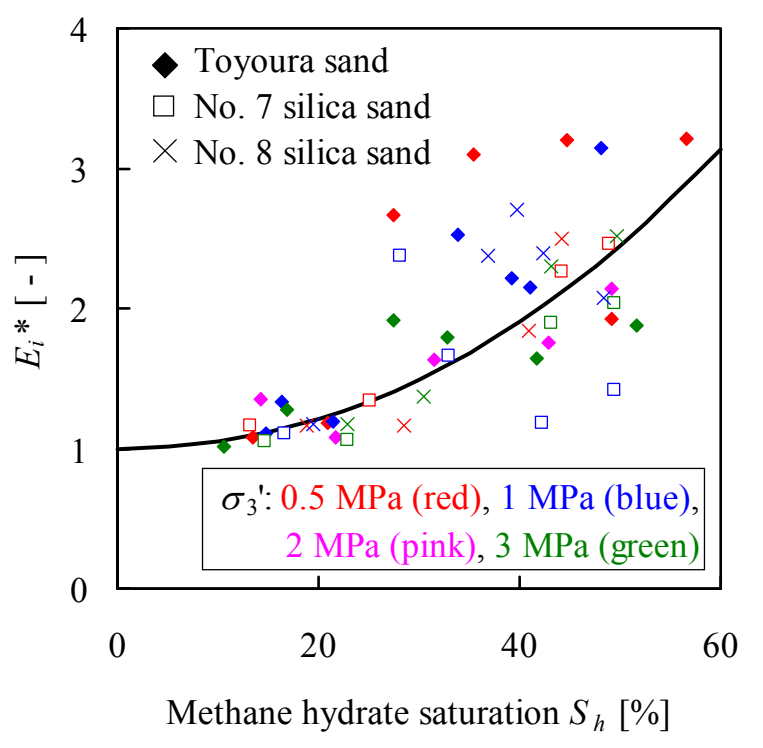

The parameter $a$ in Equation (1), or the inverse of $E_{i}$, is given by Equations (11-17). The initial tangent modulus $E_{i}$ calculated using Equations (11-17) is shown in Figure 8.

\subsection{Failure Ratio}

Duncan and Chang [21] defined the failure ratio $R_{f}$ as:

$$
R_{f}=\frac{q_{f}}{q_{u l t}}
$$

Strength $q_{f}$ can be obtained from each test result as shown in Figure 7. Asymptotic value of the deviator stress $q_{u l t}$, which is equal to the reciprocal of $b$ as expressed by Equation (3), also can be obtained from each test result, because $b$ can be determined by the linear approximation of the experimental $\left(\varepsilon_{a} / q\right)-\varepsilon_{a}$ data as seen in Equation (4). Thus $R_{f}$, which is the ratio of the strength $q_{f}$ to $q_{u l t}$, is obtained from each experimental data. Figure 10 shows $R_{f}$ plotted against $S_{h}$. Because the dependence of $R_{f}$ on $\sigma_{3}$ ' is not clear as well as a number of different soils, we assume that $R_{f}$ is independent of $\sigma_{3}{ }^{\prime} . R_{f}$ shows a weak decrease with increasing $S_{h}$. However, for simplicity, we assume that $R_{f}$ is independent of $S_{h}$ :

$$
R_{f}=0.82
$$

which is the average $R_{f}$ for the sand and hydrate-sand specimens. The data presented in Figure 10 is insufficient to determine the function form expressing the reduction in $R_{f}$ to $S_{h}$. The data for $S_{h}$ of higher than $60 \%$ is necessary to formulate $R_{f}$ more accurately. 
Figure 10. Failure ratio $R_{f}$ versus methane hydrate saturation $S_{h}$.

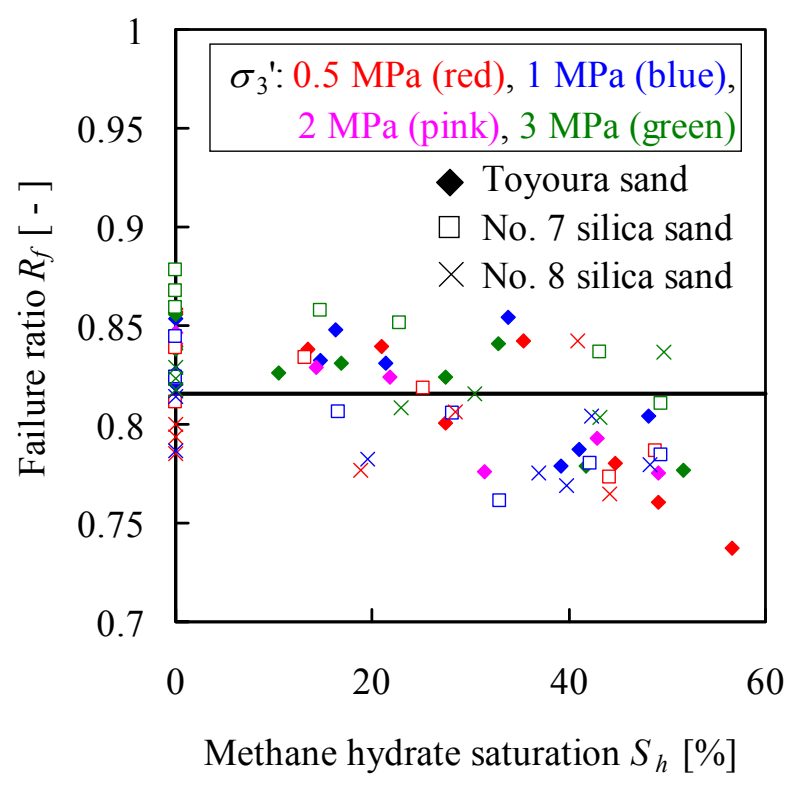

Eventually, the Duncan-Chang model (Equation (1)) may be applicable to the determination of the $q-\varepsilon_{a}$ relationship of the hydrate-sand specimens using Equations (2-3, 5-9 and 11-19).

It can be conveniently used in incremental stress analysis, because the tangent elastic modulus $E_{t}$ corresponding to any point on the $q-\varepsilon_{a}$ curve is derived in the simple form:

$$
E_{t}=\frac{\partial q}{\partial \varepsilon_{a}}=\left(1-R_{f} \frac{q}{q_{f}}\right)^{2} \cdot E_{i}
$$

\subsection{Lateral Strain}

In this section, we examine the following expression for the relationship between the lateral strain $\varepsilon_{l}$ and the axial strain $\varepsilon_{a}$ :

$$
\varepsilon_{l}=-f \cdot \varepsilon_{a}^{2}-g \cdot \varepsilon_{a}(f>0, g>0)
$$

where $f$ and $g$ are fitting parameters. The tangent Poisson's ratio $v_{t}$ and the initial tangent Poisson's ratio $v_{i}$ are expressed by:

$$
\begin{gathered}
v_{t}=-\frac{\partial \varepsilon_{l}}{\partial \varepsilon_{a}}=2 \cdot f \cdot \varepsilon_{a}+g \\
v_{i}=-\left.\frac{\partial \varepsilon_{l}}{\partial \varepsilon_{a}}\right|_{\varepsilon_{a}=0}=g
\end{gathered}
$$

Fitting prameters $f$ and $g$ can be adjusted using each experimental data on $\varepsilon_{l}-\varepsilon_{a}$ by the least-squares regression. Figure 11 shows $v_{i}$ plotted against $S_{h}$. The $S_{h}$ dependence of $v_{i}$ is weak, while the $\sigma_{3}$, dependence of $v_{i}$ is considerably apparent. Thus, we assume that $v_{i}$ is independent of $S_{h}$. Kulhawy and Duncan [23] described that $v_{i}$ generally decreases with increasing $\sigma_{3}$ ' in the form: 


$$
v_{i}=G-F \cdot \log \left(\frac{\sigma_{3}{ }^{\prime}}{p_{a}}\right)
$$

where $G=v_{i}$ at 1 atm and $F=$ the rate of change of $v_{i}$ with $\sigma_{3}$ '. We decided to apply a similar concept to Equation (24) to the dependence of $v_{i}$ on $\sigma_{3}$ ' as follows:

$$
v_{i}\left(\sigma_{3}{ }^{\prime}\right)=v_{i 1}-m \cdot \log \left(\sigma_{3}{ }^{\prime}\right)
$$

where $v_{i 1}=$ the initial tangent Poisson's ratio $v_{i}$ under $\sigma_{3}$ ' of $1 \mathrm{MPa}$; and $m=$ the coefficient determining the rate of decrease in $v_{i}$ with increasing $\log \left(\sigma_{3}{ }^{\prime}\right)$. The least-square logarithmic regression of experimental data gives the values of $v_{i 1}$ and $m$ for the sand and hydrate-sand specimens:

$$
\begin{aligned}
& v_{i 1}=\left\{\begin{array}{l}
0.394 \text { (for Toyoura sand) } \\
0.324 \text { (for No. } 7 \text { silica sand) } \\
0.253 \text { (for No. } 8 \text { silica sand) }
\end{array}\right. \\
& m=\left\{\begin{array}{l}
0.253 \text { (for Toyoura sand) } \\
0.245 \text { (for No. } 7 \text { silica sand) } \\
0.257 \text { (for No. } 8 \text { silica sand) }
\end{array}\right.
\end{aligned}
$$

Figure 12 shows $f$ plotted against $v_{i}$. Although some variation can be seen in Figure 12, $f$ appears to be approximately proportional to $v_{i}$ as:

$$
f=l \times v_{i}
$$

where $l=$ the proportional constant corresponding to the slope of the line shown in Figure 12:

$$
l=0.186
$$

Using Equation (28), Equations (21) and (22) can be rewritten as:

$$
\begin{gathered}
\varepsilon_{l}\left(\sigma_{3}{ }^{\prime}\right)=-\left(l \cdot \varepsilon_{a}{ }^{2}+\varepsilon_{a}\right) \cdot v_{i}\left(\sigma_{3}{ }^{\prime}\right) \\
v_{t}\left(\sigma_{3}{ }^{\prime}\right)=\left(2 \cdot l \cdot \varepsilon_{a}+1\right) \cdot v_{i}\left(\sigma_{3}{ }^{\prime}\right)
\end{gathered}
$$

\subsection{Calculated Deviator Stress versus Axial and Lateral Strain}

The calculated $q-\varepsilon_{a}, q-\varepsilon_{l}$ and $\varepsilon_{l}-\varepsilon_{a}$ curves for the sand specimens (a: $S_{h}=0 \%$ ) and hydrate-sand specimens (b: $S_{h}=30 \%$, c: $S_{h}=43 \%$ ) under effective confining pressures $\sigma_{3}$ ' of $0.5 \mathrm{MPa}, 1 \mathrm{MPa}$, $2 \mathrm{MPa}$ and $3 \mathrm{MPa}$ using Equations (1) and (21) are shown in Figures 1-6. It is found that the experimental $q-\varepsilon_{a}, q-\varepsilon_{l}$ and $\varepsilon_{l}-\varepsilon_{a}$ curves are reasonably reproduced by Equations (1) and (21). 
Figure 11. Initial tangent Poisson's ratio $v_{i}$ versus methane hydrate saturation $S_{h}$ for specimens formed by (a) Toyoura sand; (b) No.7 silica sand and (c) No.8 silica sand.

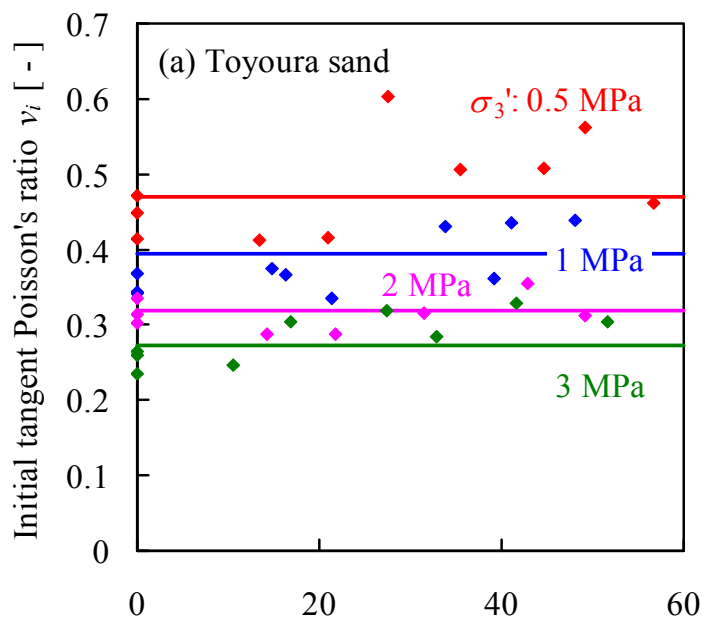

Methane hydrate saturation $S_{h}[\%]$

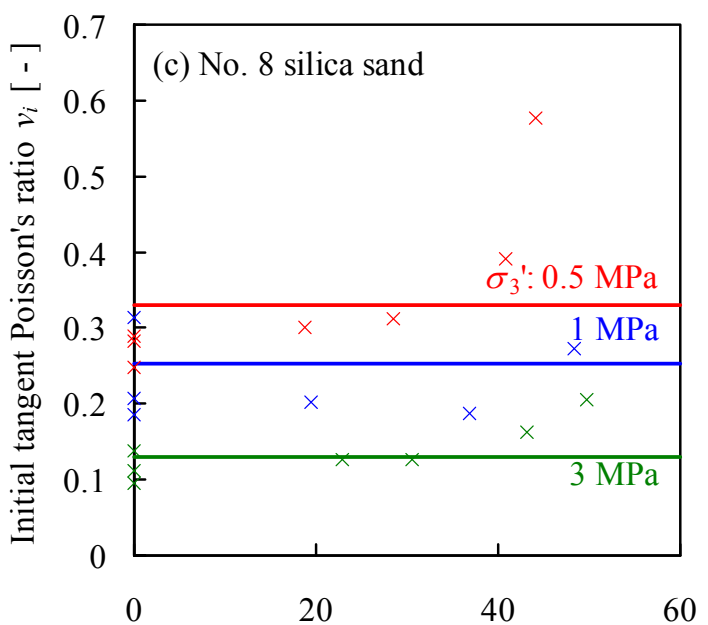

Methane hydrate saturation $S_{h}[\%]$

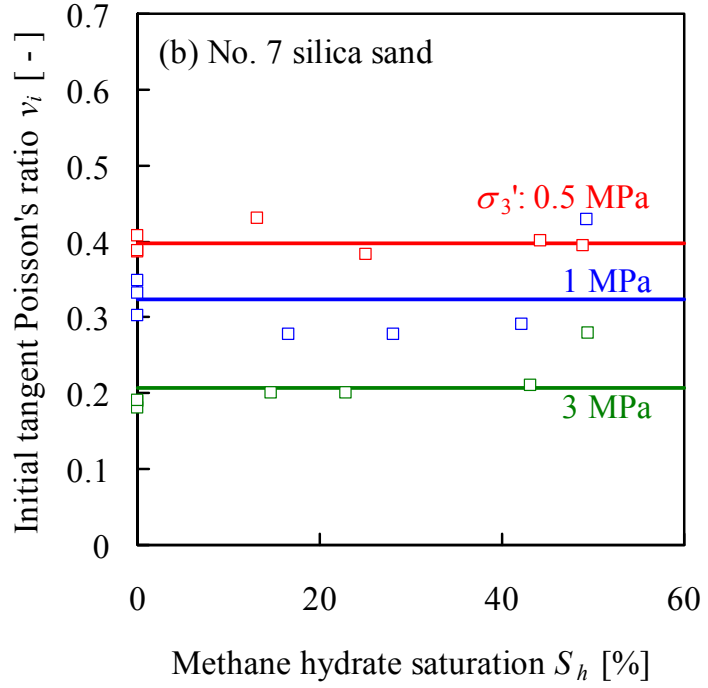

Methane hydrate saturation $S_{h}[\%]$

Figure 12. Coefficient $f$ versus initial tangent Poisson's ratio $v_{i}$. The solid line is calculated using Equation (28).

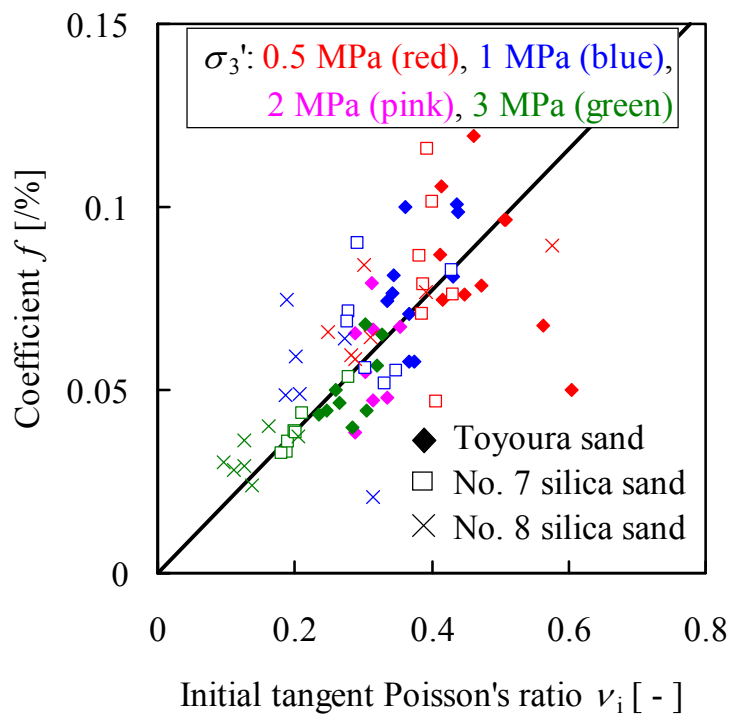




\subsection{Unloading Modulus}

The unloading modulus $E_{u r}$ is often 2 to 3 times larger than the initial tangent modulus $E_{i}$ for many geomaterials [21]. Miyazaki et al. [16] conducted unloading-reloading test on hydrate-sand specimen formed by Toyoura sand under $1 \mathrm{MPa}$ effective confining pressure to obtain $E_{u r}$. Figure 13 shows the $E_{u r}$ and $E_{i}$ under $1 \mathrm{MPa}$ effective confining pressure plotted against methane hydrate saturation $S_{h}$. The solid line denotes the calculated $e_{i}$ using Equations (13) and (15-17) for Toyoura sand specimen and the broken lines denote $k$-times the calculated $e_{i}$. It is found that the $E_{u r}$ of hydrate-sand specimen is approximately 3 to 3.5 times $E_{i}$ under $1 \mathrm{MPa}$ effective confining pressure.

Figure 13. Unloading modulus $E_{u r}$ and initial tangent modulus $E_{i}$ versus methane hydrate saturation $S_{h}$ for specimens formed by Toyoura sand under $1 \mathrm{MPa}$ effective confining pressure. The solid line denotes $e_{i}$ calculated using Equations (13) and (15-17). The broken lines are $k$-times the calculated $e_{i}$.

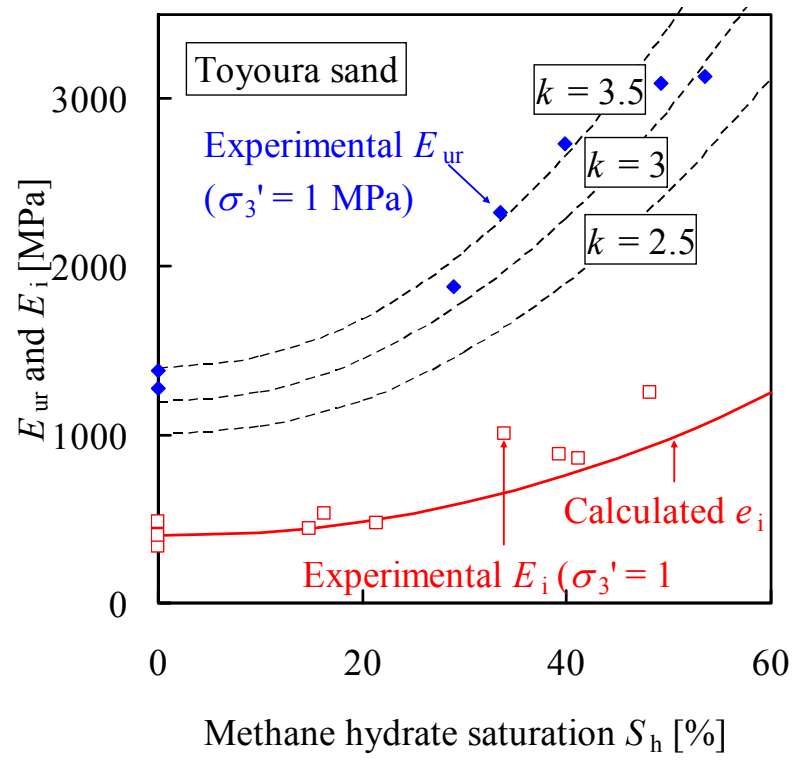

\section{Conclusions}

In this study, a nonlinear elastic model of the mechanical behavior of artificial methane-hydratebearing sediment samples was developed. The presented model is based on the Duncan-Chang model and considered the dependences of the mechanical properties on methane hydrate saturation and effective confining pressure on the basis of the experimental results reported in an earlier work [19]. Some parameters were decided depending on the type of sand forming a specimen. In addition, the plot of lateral strain versus axial strain was also formulated as a function of effective confining pressure. Volumetric strain has not been discussed in this paper. It may be possible to associate the volumetric strain calculated using the presented model with the volumetric strain measured in the experiments.

The presented model is very easy to introduce into finite element codes. The applicable range of the presented model will be validated by numerical simulations for the laboratory-scale methane hydrate dissociation experiments. 


\section{Acknowledgments}

This work was financially supported by the Research Consortium for Methane Hydrate Resources in Japan (MH21 Research Consortium) in the Japan's Methane Hydrate R\&D Program by the Ministry of Economy, Trade and Industry (METI). We appreciate insightful discussions with Akira Masui. We thank Takao Ohno and Shigenori Nagase for assistance with the experiments.

\section{References}

1. Makogon, Y.F. Hydrates of Natural Gas; Pennwell Publishing Co.: Tulsa, OK, USA, 1981.

2. Makogon, Y.F. Perspectives for the Development of Gas-Hydrate Deposits. In Proceedings of the 4th Canadian Permafrost Conference, Calgary, Canada, 1982; pp. 299-304.

3. Kvenvolden, K.A. A Major Reservoir of Carbon in the Shallow Geosphere? Chem. Geol. 1988, $71,41-51$.

4. Kvenvolden, K.A.; Ginsburg, G.D.; Soloviev, V.A. Worldwide Distribution of Subaquatic Gas Hydrates. Geo-Marine Lett. 1993, 13, 32-40.

5. Collett, T.S.; Dallimore, S.R. Detailed Analysis of Gas Hydrate Induced Drilling and Production Hazards. In Proceedings of the 4th International Conference on Gas Hydrates, Yokohama, Japan, 2002; pp. 47-52.

6. Bugge, T.; Belderson, R.H.; Kenyon, N.H. The Storegga Slide. Phil. Trans. Royal Soc. A 1988, 325, 357-388.

7. Kleinberg, R.L. Mechanical Stability of Seafloor Sediments with Application to Gas Hydrate Deposits. In Proceedings of the 5th International Conference on Gas Hydrates, Trondheim, Norway, 2005; pp. 736-748.

8. Sakamoto, Y.; Shimokawara, M.; Ohga, K.; Miyazaki, K.; Tenma, N.; Komai, T.; Aoki, K.; Yamaguchi, T. Field Scale Simulation for Consolidation and Gas Production Behavior during Depressurization Process of Methane Hydrate in Marine Sediments. In Proceedings of the 2008 Offshore Technology Conference, Houston, TX, USA, 2008; OTC19283.

9. Klar, A.; Soga, K.; Ng, M.Y.A. Coupled Deformation-Flow Analysis for Methane Hydrate Extraction. Geotechnique 2010, 60, 765-776.

10. Winters, W.J.; Pecher, I.A.; Booth, J.S.; Mason, D.H.; Relle, M.K.; Dillon, W.P. Properties of Samples Containing Natural Gas Hydrate from the JAPEX/JNOC/GSC Mallik 2L-38 Gas Hydrate Research Well, Determined using Gas Hydrate and Sediment Test Laboratory Instrument (GHASTLI). Bull. Geol. Sur. Can. 1999, 544, 241-250.

11. Winters, W.J.; Waite, W.F.; Mason, D.H.; Kumar, P. Physical Properties of Repressurized Samples Recovered during the National Gas Hydrate Program Expedition Offshore India. In Proceedings of the 6th International Conference on Gas Hydrates, Vancouver, Canada, 2008.

12. Masui, A.; Miyazaki, K.; Haneda, H.; Ogata, Y.; Aoki, K. Mechanical Characteristics of Natural and Artificial Gas Hydrate Bearing Sediments. In Proceedings of the 6th International Conference on Gas Hydrates, Vancouver, Canada, 2008. 
13. Winters, W.J.; Waite, W.F.; Mason, D.H.; Gilbert, L.Y.; Pecher, I.A. Effect of Grain Size and Pore Pressure on Acoustic and Strength Behavior of Sediments Containing Methane Gas Hydrate. In Proceedings of the 5th International Conference on Gas Hydrates, Trondheim, Norway, 2005; pp. 507-516.

14. Masui, A.; Haneda, H.; Ogata, Y.; Aoki, K. Effects of Methane Hydrate Formation on Shear Strength of Synthetic Methane Hydrate Sediments. In Proceedings of the 15th International Offshore and Polar Engineering Conference, Seoul, Korea, 2005; pp. 364-369.

15. Hyodo, M.; Nakata, Y.; Yoshimoto, N.; Ebinuma, T. Basic Research on the Mechanical Behavior of Methane Hydrate-Sediments Mixture. Soils Found. 2005, 45, 75-85.

16. Miyazaki, K.; Masui, A.; Tenma, N.; Ogata, Y.; Aoki, K.; Yamaguchi, T.; Sakamoto, Y. Study on Mechanical Behavior for Methane Hydrate Sediment Based on Constant Strain-Rate Test and Unloading-Reloading Test Under Triaxial Compression. Int. J. Offshore Polar Eng. 2010, 20, $61-67$.

17. Miyazaki, K.; Masui, A.; Aoki, K.; Sakamoto, Y.; Yamaguchi, T.; Okubo, S. Strain-Rate Dependence of Triaxial Compressive Strength of Artificial Methane-Hydrate-Bearing Sediment. Int. J. Offshore Polar Eng. 2010, 20, 256-264.

18. Miyazaki, K.; Masui, A.; Sakamoto, Y.; Tenma, N.; Yamaguchi, T. Effect of Confining Pressure on Triaxial Compressive Properties of Artificial Methane Hydrate Bearing Sediments. In Proceedings of the 2010 Offshore Technology Conference, Houston, TX, USA, 2010; OTC20721.

19. Miyazaki, K.; Masui, A.; Sakamoto, Y.; Aoki, K.; Tenma, N.; Yamaguchi, T. Triaxial Compressive Properties of Artificial Methane-Hydrate-Bearing Sediment. J. Geophys. Res. 2011, 116, B06102.

20. Miyazaki, K.; Aoki, K.; Tenma, N.; Sakamoto, Y.; Yamaguchi, T. Application of Nonlinear Elastic Constitutive Model to Analysis of Artificial Methane-Hydrate-Bearing Sediment Sample. In Proceedings of the 9th ISOPE Ocean Mining Symposium, Maui, HA, USA, 2011; pp. 15-20.

21. Duncan, J.M.; Chang, C.Y. Nonlinear Analysis of Stress and Strain in Soils. J. Soil Mech. Found. Div. 1970, 96, 1629-1653.

22. Janbu, N. Soil Compressibility as Determined by Oedometer and Triaxial Test. In Proceedings of the 3rd European Conference on Soil Mechanics and Foundation Engineering, Wiesbaden, Germany, 1963; pp. 19-25.

23. Kulhawy, F.H.; Duncan, J.M. Stresses and Movements in Oroville Dam. J. Soil Mech. Found. Div. 1972, 98, 653-665.

(C) 2012 by the authors; licensee MDPI, Basel, Switzerland. This article is an open access article distributed under the terms and conditions of the Creative Commons Attribution license (http://creativecommons.org/licenses/by/3.0/). 